\title{
Variation in Anther Extrusion and Its Impact on Fusarium Head Blight and Deoxynivalenol Content in Oat (Avena sativa L.)
}

\author{
Selamawit Tekle ${ }^{1}$, Sissela Stråbø Schofer ${ }^{1}$, Xinyao He ${ }^{1,2} \oplus$, Yanhong Dong ${ }^{3}$ and \\ Åsmund Bjørnstad 1,* \\ 1 Faculty of Biosciences, Department of Plant Sciences, Norwegian University of Life Sciences, P. O. Box 5003, \\ NO-1432 Ås, Norway; selamppdf@yahoo.com (S.T.); sissela.strabo@gmail.com (S.S.S.) \\ 2 International Maize and Wheat Improvement Center (CIMMYT), Carretera México-Veracruz Km. 45, \\ El Batán, Texcoco 441, Mexico; X.He@cgiar.org \\ 3 Department of Plant Pathology, University of Minnesota, St. Paul, Minnesota, MN 55108, USA; \\ dongx001@umn.edu \\ * Correspondence: asmund.bjornstad@nmbu.no; Tel.: +047-48180054
}

Received: 30 January 2020; Accepted: 2 March 2020; Published: 4 March 2020

\begin{abstract}
Variation and inheritance of anther extrusion and its effects on Fusarium head blight were studied. On a 0 to 9 scale, variation ranged from 1 to 6 in a North American oat panel and from 0 to 8 in a Nordic population. The inheritance was studied in two recombinant inbred line populations $($ Fiia $\times$ Stormogul and Svea $\times$ Stormogul). Fiia and Svea are recent white-seeded cultivars with low to medium anther extrusion, while Stormogul is an old black-seeded cultivar with high anther extrusion. Highly significant transgressive segregations and high heritabilities were observed $\left(h^{2}=0.91\right.$ in Fiia $\times$ Stormogul and $h^{2}=0.83$ in Svea $\times$ Stormogul). Another extrusion was negatively correlated with Fusarium head blight and deoxynivalenol in spawn-inoculated field experiments, but significantly only in Fiia $\times$ Stormogul where the range in resistance was widest. Correlations were reversed in spray-inoculated greenhouse experiments, apparently spraying open florets defeated the avoidance mechanism. Anther extrusion may help oat avoid Fusarium infection in the field, but the genetic variance is inadequate and high anther extrusion is rare in modern genepools.
\end{abstract}

Keywords: anther extrusion; anther retention; Deoxynivalenol; Fusarium head blight; spray inoculation; spawn inoculation

\section{Introduction}

Cultivated oat (Avena sativa L.) is an important crop in cool and moist climates of northern Europe and North America. Traditionally a feed crop, oat is now recognized as health food due to its high nutritional quality and health promoting compounds such as soluble dietary fiber and antioxidants [1-3]. An oat-including diet is shown to lower plasma cholesterol and reduce the risk of cardiovascular diseases, diabetes, and cancers [2,3]. However, in the past decade, the occurrence of mycotoxins in oat have received increasing attention, especially in the Nordic countries, where both shortage of certified seed due to reduced germination percentage and high toxin levels in harvested grains have been major issues. To overcome this, both the etiology of disease [4] and the resistance [5,6] have been studied. Breeding has reduced mycotoxin levels by $40 \%$ [7], but the mechanisms are not well understood.

The oat panicle comprises the rachis or the main stem, the pedicels attached at the rachis nodes, and rachilla that joins each spikelet to the pedicels. Each spikelet is composed of one to several florets sitting on opposite sides of the rachilla. Flowering in oat begins in the uppermost spikelet and from 
the pedicel tips and continues towards the base of the panicle, taking longer flowering period ( 8 to 10 days) than wheat and barley (3-5 days). Within a spikelet, primary florets flower before secondary florets and so on $[8,9]$. Given optimal temperature and humidity, flowering usually occurs in the afternoon approximately one hour after maximum day temperature and lasts for about half an hour to one hour [8].

In open flowering (chasmogamous) grasses, lodicules swell and push the lemma and the palea apart, while filaments elongate pushing the anthers out of the floret. Lodicules lose their turgidity after 30-60 min following anthesis, leading to complete or partial closure of the florets $[8,10]$. With sufficient flower opening and filament elongation, anthers will be fully extruded. Anthers may be caught between the palea and the lemma if the degree and/or the duration of flower opening are not sufficient [8]. On the other hand, in truly cleistogamous genotypes (e.g. with the Cly1 gene in barley), the lodicules do not swell [11], thus, anthers remain inside florets until they are pushed by the developing caryopsis after 10 days; then, infection may occur [12].

Anther extrusion (AE) is strongly dependent on environmental factors. Drought increased closed flowering florets in barley, while high AE was observed in humid or well-watered environments [12]. Given the presumed role of anthers in etiology of disease (see below), anther retention (AR) could be a more accurate predictor [13,14]. However, scoring open flowering width [15] or AR is very cumbersome. Fortunately, AE is a good proxy in well-watered plants and the erect spikes of wheat [16]. With the protracted flowering period and the different panicle morphology of oat, this is unknown.

The degree of flower opening and AE affects resistance to diseases. In wheat and oat, the internal surfaces of the palea and lemma and the caryopsis are easily penetrable by Fusarium spp. compared to the highly lignified external surfaces $[4,17,18]$. This may make open flowering genotypes more susceptible to Fusarium infection compared to close flowering [15]. Conversely, wheat and barley genotypes with closed flowering or complete AE are more resistant to Fusarium head blight (FHB) compared to genotypes that retain their anthers between the palea and lemma $[16,19]$.

Studies on the infection process of F. graminearum and F. langsethiae in oat confirmed that dead anthers are indeed infection foci for Fusarium [4,20], reflecting the predominantly saprophytic nature of Fusarium spp. Hyphal growth of F. langsethiae on the surfaces of the palea, lemma, and glumes of oat florets was also facilitated by the presence of pollen [20]. Like other small-grained cereals, infection in oat occurs in single spikelets, but spread of infection from spikelet to spikelet via the long pedicels is rare. The effect of AE on FHB and Deoxynivalenol (DON) content depends on genetic and environmental factors. In wheat, Skinnes et al. found that genotypes with low AE may show a wide range of DON levels and field FHB scores depending on their resistance level and the environment, but genotypes with high AE usually had low FHB and DON levels [16].

The objectives of the experiments reported in this paper are to study (i) the variation of AE in two populations of oat accessions; (ii) the inheritance of AE in two Recombinant Inbred Line (RIL) populations; and (iii) the effect of AE on Fusarium infection and DON content in oat.

\section{Materials and Methods}

\subsection{Variation in Anther Extrusion in Two Populations of Oat Accessions}

\subsubsection{The North American AFRI CORE Oat Panel}

This panel comprised 418 (mostly North American but some European) accessions previously analyzed for DON and FHB in 2011 and 2012 (for details, see [5]) using an un-replicated augmented design with 12 rows, 40 columns, and eight blocks, each containing the same set of two moderately resistant (Hurdal and Leggett) and four susceptible checks (Bessin, Gem, Ogle, and Horizon270). This gave eight independent values for each of the six checks. To assess $\mathrm{AE}$, all accessions were planted in hill plots in the field in 2013, using the same augmented design, but with 96 randomly selected lines added in two replications to improve error estimation. In 2014, a greenhouse experiment was conducted using similar experimental design except that the check cultivars Bessin (Germany) and 
Leggett (Canada) were replaced by the high AE cultivar Norum (Norway) and low AE cultivar Typhon (Germany). AE was scored in a similar way as described in [16] i.e., estimation was done at full flowering stage by visual scoring using a linear scale of $0-9$, with 0 for none and 9 for all anthers extruded. Best Linear Unbiased Prediction (BLUP) values were then calculated for AE.

\subsubsection{The Nordic Screening Population}

This population comprised 146 accessions mostly from the Nordic countries (83) (including the set used by He \& Bjørnstad [21], but also accessions from all over the world. Accessions spanned from the late 19th to the early 21st century. The population was sown in pots in the greenhouse on December 21st 2013, in a randomized complete block design with two full replications. Accessions were phenotyped for AE, days to flowering (DTF), and hull color.

\subsection{The Variation and Inheritance of Anther Extrusion in Two Recombinant Inbred Line Populations}

Two RIL populations were developed from the crosses Fiia by Stormogul ( $\times$ S, 148 RIL) and Svea by Stormogul (S $\times$ S, 148 RIL). Stormogul is an old black-seeded Swedish cultivar (Svalöf AB, 1901) made by pure line selection in 'Plym black tartar' [22]. It represents the Nordic black oat genepool [0] and is known to be tolerant to early summer drought due to delayed flowering [2]. Svea (Svalöf AB, 1976) and Fiia (Boreal Plant Breeding Ltd, 2002), are more recent white-seeded varieties released in Sweden and Finland, respectively.

The $\mathrm{F} \times \mathrm{S} \mathrm{F}_{6: 8}$ RIL population was phenotyped thrice, in 2012, 2013, and 2015, and the $\mathrm{S} \times \mathrm{S}$ population twice, in 2012 and 2013. In 2012, the experiments were sown in late April. Ten seeds from each RIL were sown in pots in a temperature-regulated greenhouse. The pots of each population were arranged in 11 columns $\times 14$ rows using an augmented design. The parents of the respective crosses and Hurdal were used as checks and were replicated twice. In 2013, the experiments were sown in early August using the same procedure as in 2012, except the augmented design was expanded to include five checks (the respective parents and the cultivars Hurdal, Typhon, and Norum) replicated four times. The pots of each population were then arranged in an augmented design with 14 columns and 12 rows.

In 2015, $134 \mathrm{~F}_{6: 9}$ RIL from the $148 \mathrm{~F} \times \mathrm{S}$ population were tested for the third time to assess the relationship between anther retention (AR) and visible (apparent) AE. The seeds were sown in the greenhouse in early June using an augmented design with 32 columns and five rows. The parents Fiia and Stormogul and the cultivars Typhon and Norum were used as checks, replicated five times. Since flowering took place in the peak field season, it was impractical to spend 1-2 hours every afternoon observing AE, for which we already had two independent estimates. Instead, AR was used to estimate $A E^{*}$ : three panicles from each pot were sampled one week after the beginning of flowering and the number of anthers remaining (AR) in both primary and secondary florets were counted. The average number of extruded anthers were calculated by subtracting the average number of remaining anthers from 3 (total number of anthers in a floret). To be able to compare results with 2012 and 2013 data on a $0-9$ scale, 2015 data were converted as $\mathrm{AE}^{*}=2.71^{(3-\mathrm{AR})}$. DTF was noted as days from sowing when all the main tillers emerged from the boot leaf and when at least one floret had flowered. Hull color was scored as white, yellow, or brown (all shades of brown), and plant height $(\mathrm{PH})$ was measured from the soil to the base of the main panicles (data not reported).

\subsection{Statistical Analysis}

Analysis of variance (ANOVA) of phenotypic data was carried out with the PROC GLM module in SAS program ver. 9.2 (SAS Institute, Inc., Cary, NC, USA) according to Scott and Milliken [23]. Best linear unbiased prediction (BLUP) values were calculated using the solution function in the PROC MIXED module. From the ANOVA, heritability were estimated, $h^{2}=\sigma_{g}^{2} /\left(\sigma_{g}^{2}+\sigma_{e}^{2} / r\right)$ for a single year and $h^{2}=\sigma_{g}^{2} /\left(\sigma_{g}^{2}+\sigma_{g+y}^{2} / y+\sigma_{e}^{2} / r y\right)$ for multiple years, in which $\sigma_{g}^{2}$ stands for genetic variance, 
$\sigma_{g+y}^{2}$ for genotype-by-year interaction, $\sigma_{e}^{2}$ for error variance, $\mathrm{y}$ for the number of years, and $\mathrm{r}$ for the number of replications.

\subsection{The Effect of Anther Extrusion on Fusarium Infection and DON Content}

DTF and PH are both confounding factors for FHB infection [6]. Therefore, subsets of 16 RILs from each of the two populations that covered the whole range of AE from 0-9 but differed in DTF only by 1-2 days (PH was allowed to vary). With their parents, the RILs were tested in field and greenhouse trials to see the effect of AE on Fusarium infection and DON accumulation. The cultivars Bessin, Odal, Typhon, and Norum were used as checks in the different experiments. The cultivar Bessin is highly susceptible to FHB while the cultivar Odal is moderately resistant.

\subsubsection{Spawn-Inoculated Field Experiments}

Spawn-inoculated field experiments were carried out in 2015 at the Vollebekk research farm, Norwegian University of Life Sciences ( $59^{\circ} 39^{\prime} \mathrm{N}, 10^{\circ} 39^{\prime} \mathrm{E}$ ), as previously described in [7]. The RIL from each cross were tested in two separate experiments using an alpha lattice experimental design with two replications sown early May. Each plot was sown with 50-gram seed in four rows spaced $0.15 \mathrm{~m}$ apart. A compound fertilizer (NPK 21-4-10) was applied just before planting at the rate of $400 \mathrm{~kg} / \mathrm{ha}$. Fusarium graminearum-infected oat kernels were used as spawn inoculum and applied at a rate of $10 \mathrm{~g} / \mathrm{m}^{2}$ at Zadoks growth stage 31/32 [24]. Plots were mist irrigated following inoculation until 10 days after the last flowering date. DTF, PH, and FHB were scored during the field season. Disease (field FHB symptom) was scored twice on a plot basis with a $0-5$ whole digit scale. Plots with no visible symptoms were given the score zero, while plots with more than $50 \%$ diseased spikelets (visually estimated, not counted as incidence) were given a score of five. The first FHB scoring was done at 22 to 25 days after flowering, the second scoring was done one week later. AE could not be scored directly, since the mist irrigation (plus rain and wind) makes it unreliable. Instead, five fully flowered panicles were sampled randomly approximately one week after flowering from each plot and were used to score $\mathrm{AR}$ and used to estimate $\mathrm{AE}^{*}$, as explained above.

\subsubsection{Spray-Inoculated Greenhouse Experiment}

From the $\mathrm{F} \times \mathrm{S}$ population, only 10 of the 16 RILs used in the field experiment, the parents, and two checks (Typhon and Norum) were evaluated in a spray-inoculated greenhouse experiment using a randomized complete block design with three replicates (pots of 10 plants) sown mid-February 2015. DTF and AE were observed every afternoon from the onset of anthesis. Plants were spray inoculated during open flowering with macroconidial suspension of $F$. graminearum of $10^{5}$ spores $/ \mathrm{mL}$ using a handheld sprayer. Inoculum was produced following the protocol described in Tekle et al. [25]. All tillers and lower panicle branches were removed prior to inoculation to avoid late flowering spikelets. Each pot received about $10 \mathrm{~mL}$ inoculum. Following inoculation, pots were put under plastic tents for three days. Panicles were misted regularly to increase the relative humidity under the plastic tents and to facilitate infection. One panicle from each pot was sampled two weeks after flowering and AR measured. FHB symptoms were scored two weeks after inoculation as number of symptomatic spikelets per total number of spikelets. A spawn experiment parallel to the spray inoculation experiment would have been desirable, but not possible for occupational safety reasons, since it would involve high concentrations of ascospores released in the greenhouse air.

Deoxynivalenol content of samples from both field and greenhouse experiments were determined by gas chromatography coupled with mass spectrometry following the protocol described by [26,27], from a four-gram ground subsample at the Department of Plant Pathology, University of Minnesota. Analysis of variance of phenotypic data was carried out and BLUP values were calculated using the solution function in SAS program ver. 9.2 (SAS Institute, Inc., Cary, NC, USA) using the PROC MIXED module. The parents were not included in correlations analysis. 


\section{Results}

\subsection{The Variation in Anther Extrusion}

\subsubsection{The AFRI CORE Screening Population}

The ANOVA revealed significant differences in AE between genotypes (Table 1) with marginally significant differences between years (means 3.6 and 3.9). Most of the accessions in this population had low AE (Figure 1), ranging from 1.2 to 6.3 in the 2013 field experiment and from 0.5 to 6.6 in the 2014 greenhouse experiment. The repeatability was only modest $(r=0.39, p<0.0001)$, reflecting the frequent deviations of two or more units in phenotypes with low (1-4) AE. Fusarium head blight and DON were uncorrelated with AE (data not shown). Still, like in wheat [16] a 'fan-shape' distribution pattern could be discerned for DON vs. AE. Lines with low AE demonstrated a wide range of DON values, while those with high AE most often had lower DON values (Figure 2). This was interpreted as high AE contributing to avoidance, whereas with low AE, active resistance factors may prevent infection. Therefore, the scattering is important, not the correlation coefficient.

Table 1. Analysis of variance of anther extrusion in the AFRI CORE population.

\begin{tabular}{cccccc}
\hline Traits & Source & DF & Mean Square & $\boldsymbol{F}$ Value & $\boldsymbol{P}$ Value \\
\hline \multirow{2}{*}{2013} & Genotype & 430 & 3.28 & 2.35 & $<0.0001$ \\
& Check & 6 & 4.98 & 3.57 & 0.0026 \\
& Block & 7 & 0.89 & 0.64 & 0.7239 \\
& Error & 130 & 1.40 & & \\
\multirow{5}{*}{2014} & Genotype & 421 & 4.79 & 4.02 & $<0.0001$ \\
& Check & 6 & 36.98 & 31.03 & $<0.0001$ \\
& Block & 7 & 2.24 & 1.88 & 0.1066 \\
& Error & 32 & 1.19 & & \\
& Genotype & 430 & 5.47 & 2.46 & $<0.0001$ \\
& Check & 8 & 30.93 & 13.94 & $<0.0001$ \\
& Year & 1 & 9.33 & 4.20 & 0.0408 \\
& Block (Year) & 14 & 2.80 & 1.26 & 0.2254 \\
& Error & 587 & 2.22 & & \\
\hline
\end{tabular}

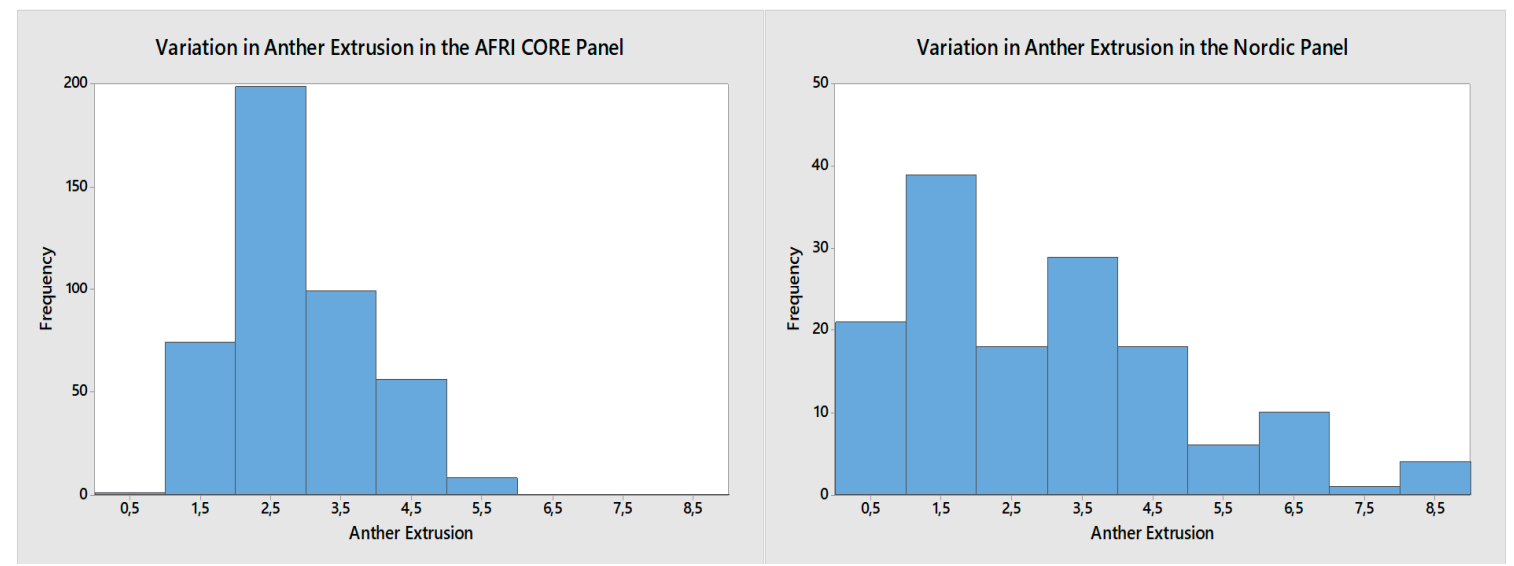

Figure 1. Distribution of BLUP values for anther extrusion in the North American AFRI CORE oat screening panel (Left) and the Nordic oat screening panel (Right). Anther extrusion was scored on a 0-9 scale. Note the more limited range in the AFRI CORE. 


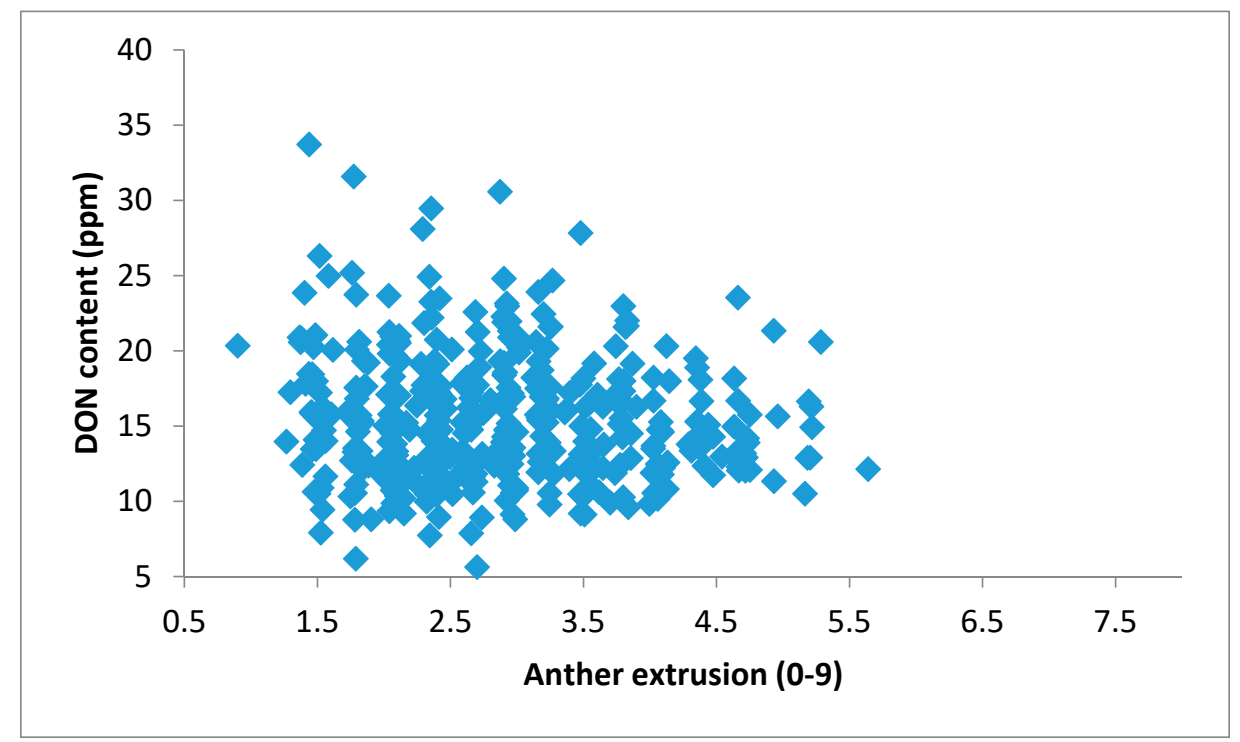

Figure 2. Distribution of anther extrusion versus deoxynivalenol content in the AFRI CORE oat population. Note the "fan shape" towards lower DON with higher AE, whereas low AE may have low to high DON levels, despite the limited range in AE.

\subsubsection{The Nordic Screening Population}

There were significant differences between genotypes $(p<0.001)$ for AE and a high correlation between replicates $(r=0.78, p<0.0001)$. The mean AE of genotypes ranged from 0 to 8.5 (Figure 1 ), with some large deviations at lower values. Most accessions (111 out of 140) had mean AE between zero and four, while only 14 accessions, one of which Stormogul, exceeded six. Cultivars Gere and Bessin, highly susceptible to FHB [28], had mean AE values of one. Anther extrusion was uncorrelated to DTF. Black lemma and high AE were associated in old genotypes.

\subsection{The Variation and Inheritance in Anther Extrusion and Days to Flowering in the Recombinant Inbred} Line Populations

There were statistically significant differences between RILs $(p<0.0001)$ for both AE and DTF in both populations (Table 2). AE showed continuous variation with transgressive segregation (not in the $\mathrm{F} \times \mathrm{S}$ population in 2012). This is consistent with an apparent heterosis in AE (score 8-9) and $\mathrm{PH}$ (Stormogul ca. $175 \mathrm{~cm}, \mathrm{~F} 1225 \mathrm{~cm}$ ) in the greenhouse grown F1 plants from which our RILs were derived (results not shown). The association between black lemma and high AE in the RILs was weak.

There were no Year and Check*Year effects when only 2012 and 2013 data were analyzed, showing the stability of the AE as a trait (Table 2). However, when the $2015 \mathrm{AE}$ data for the $\mathrm{F} \times \mathrm{S}$ population were included, the year effect was pronounced ( $p<0.0001$, not shown). Anther extrusion had a different distribution in 2015 since $\mathrm{AE}^{*}$ was calculated from AR. In 2015, the mean AE for the RILs were 3.2, while the parents Fiia and Stormogul scored a mean AE of 1.7 and 2.6, respectively. 
Table 2. Analysis of variance for AE- anther extrusion and DTF (days to flowering) in the Fiia $\times$ Stormogul $(\mathrm{F} \times \mathrm{S})$ and Svea $\times$ Stormogul $(\mathrm{S} \times \mathrm{S})$ recombinant inbred line populations tested during 2012 and 2013.

\begin{tabular}{|c|c|c|c|c|c|c|}
\hline & Traits & Source & DF & Mean Square & F Value & $P$ Value \\
\hline \multirow{14}{*}{$\mathrm{F} \times \mathrm{S}$} & $\mathrm{AE}$ & Genotype (Check) & 145 & 7.56 & 6.83 & $<0.0001$ \\
\hline & \multirow{13}{*}{ DTF } & Check & 5 & 25.83 & 23.36 & $<0.0001$ \\
\hline & & Year & 1 & 1.52 & 1.37 & 0.2430 \\
\hline & & Block (Year) & 4 & 0.85 & 0.77 & 0.5475 \\
\hline & & Column (Year) & 23 & 0.81 & 0.73 & 0.8036 \\
\hline & & Check*Year & 3 & 2.07 & 1.87 & 0.1374 \\
\hline & & Error & 134 & 1.11 & & \\
\hline & & Genotype (Check) & 145 & 69.24 & 4.01 & $<0.0001$ \\
\hline & & Check & 5 & 423.18 & 24.50 & $<0.0001$ \\
\hline & & Year & 1 & 67.54 & 3.91 & 0.0501 \\
\hline & & Block (Year) & 4 & 26.66 & 1.54 & 0.1932 \\
\hline & & Column (Year) & 23 & 7.16 & 0.41 & 0.9917 \\
\hline & & Check*Year & 3 & 9.88 & 0.57 & 0.6344 \\
\hline & & Error & 133 & 17.27 & & \\
\hline \multirow{13}{*}{$S \times S$} & \multirow[t]{7}{*}{$\mathrm{AE}$} & Genotype (Check) & 138 & 5.75 & 6.01 & $<0.0001$ \\
\hline & & Check & 5 & 30.03 & 31.40 & $<0.0001$ \\
\hline & & Year & 1 & 1.37 & 1.44 & 0.2328 \\
\hline & & Block (Year) & 4 & 2.49 & 2.60 & 0.0393 \\
\hline & & Column (Year) & 23 & 1.1124 & 1.16 & 0.2905 \\
\hline & & Check*Year & 3 & 1.59 & 1.66 & 0.1779 \\
\hline & & Error & 128 & 0.96 & & \\
\hline & \multirow[t]{6}{*}{ DTF } & Genotype (Check) & 147 & 131.67 & 3.50 & $<0.0001$ \\
\hline & & Check & 5 & 498.13 & 13.25 & $<0.0001$ \\
\hline & & Year & 1 & 276.71 & 7.36 & 0.0075 \\
\hline & & Block (Year) & 4 & 19.13 & 0.51 & 0.7295 \\
\hline & & Column (Year) & 23 & 27.93 & 0.74 & 0.7941 \\
\hline & & Check*Year & 3 & 98.72 & 2.63 & 0.0530 \\
\hline
\end{tabular}

Statistically significant $(p<0.01)$ medium to high correlations were found between experimental years for both $\mathrm{AE}\left(\mathrm{AE}^{*}\right)$ and DTF in both RIL populations (Table 3$)$. Anther extrusion was not correlated to DTF. Heritability of AE was high in both RIL populations $\left(h^{2}=0.91\right.$ in $\mathrm{F} \times \mathrm{S}$ and $h^{2}=0.83$ in $\left.\mathrm{S} \times \mathrm{S}\right)$, of the same order as DTF $\left(h^{2}=0.87\right.$ in $\mathrm{F} \times \mathrm{S}, h^{2}=0.65$ in the $\left.\mathrm{S} \times \mathrm{S}\right)$. Anther retention was found to be a good proxy to anther extrusion, with similar correlations over environments $(r=0.70-0.74$ across years, except for 0.58 in AE12 vs. AE*15) and in magnitude slightly lower than DTF.

Table 3. Correlation coefficients $(p<0.01)$ among different experimental years of anther extrusion (AE and $\mathrm{AE}^{*}$, with years indicated), days to flowering (DTF), and plant height (PH) of the Fiia by Stormogul $(\mathrm{F} \times \mathrm{S})$ and Svea by Stormogul $(\mathrm{S} \times \mathrm{S})$ recombinant inbred line populations. (AE*: Anther extrusion data in 2015 calculated from average number of retained anthers (AR) from five panicles sampled randomly from each plot using the formula $\mathrm{AE}=2.71(3-\mathrm{AR}))$.

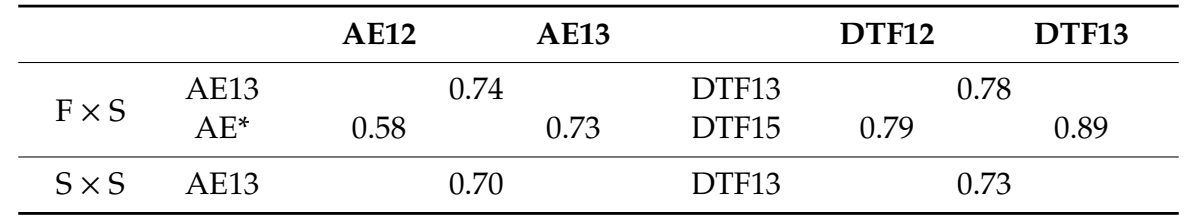

The markedly later DTF in Stormogul has been subject of breeding research, since it was long used by farmers for its tolerance to early summer drought [22] a trait breeder found hard to separate from lateness. In both populations, (Figure 3) some extremely late transgressive RILs occurred with mean DTF values up to 90 days, exceeding 100 days in 2013, but less than a week in 2012. This year effect was significant in $\mathrm{S} \times \mathrm{S}$, but only marginally in $\mathrm{F} \times \mathrm{S}$ and did not cause a Check ${ }^{*}$ Year interaction (Table 2). 

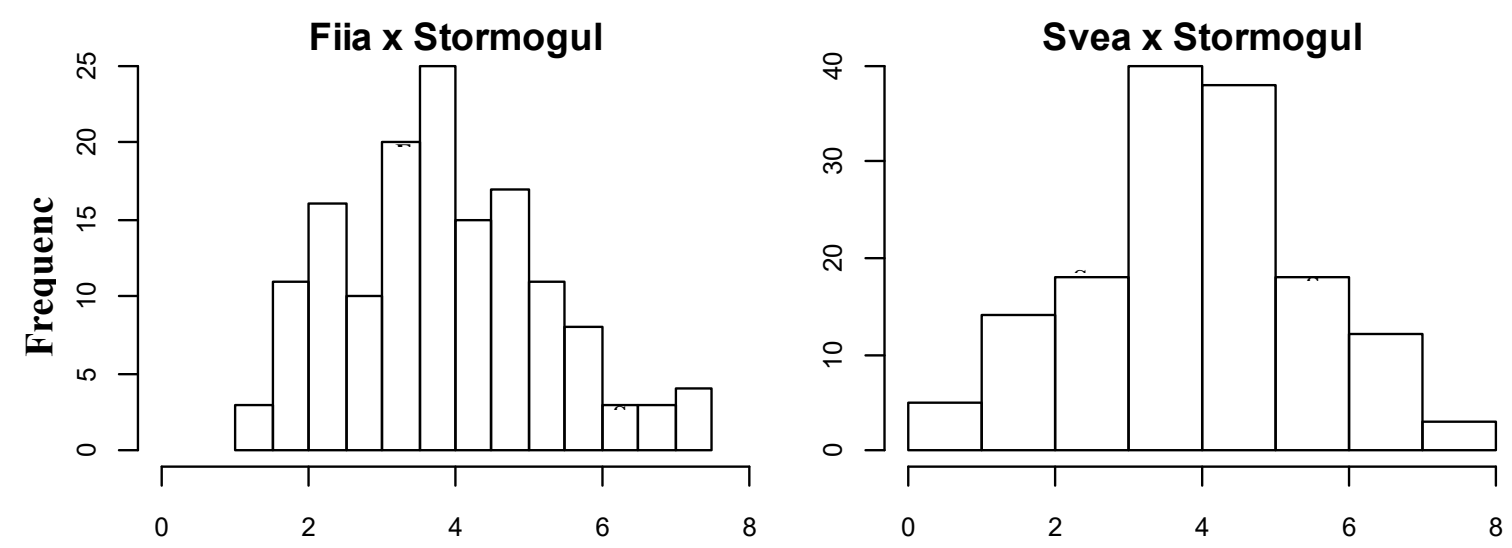

Anther Extrusion (0-9)

Figure 3. Distribution of BLUP values for days to flowering in the Fiia by Stormogul (Left) and Svea by Stormogul (Right) recombinant inbred line populations (data averaged for 2012 and 2013).

\subsection{The Effect of Anther Extrusion on Fusarium Head Blight}

\subsubsection{Spawn-Inoculated Field Experiments}

Analysis of variance showed statistically significant differences between the entries for DON, $\mathrm{FHB}$, and DTF in both $\mathrm{F} \times \mathrm{S}$ and $\mathrm{S} \times \mathrm{S}$ trials $(p<0.05)$. DON levels ranged from 3.0 to $24.7 \mathrm{ppm}$ in the $\mathrm{F} \times \mathrm{S}$ trial, and Stormogul and Fiia had mean DON value of $4.8 \mathrm{ppm}$ and $11.8 \mathrm{ppm}$, respectively. As seen in Figure 4, genotypes with the highest DON values often had low $\mathrm{AE}^{*}$, with some exceptions in the intermediate DON values. The $\mathrm{S} \times \mathrm{S}$ cross was overall more susceptible. DON ranged from 5.2 to $39.1 \mathrm{ppm}$, and Stormogul and Svea had DON values of $5.3 \mathrm{ppm}$ and $31.7 \mathrm{ppm}$, respectively. The $\mathrm{S} \times \mathrm{S}$ population was more susceptible (mean $\mathrm{DON}=18.7 \mathrm{ppm}$ ) than the $\mathrm{F} \times \mathrm{S}$ (mean $\mathrm{DON}=9.9 \mathrm{ppm}$ ), and the range in $\mathrm{AE}^{*}$ was less, despite the similarity between the AE plots in Figure 5 .

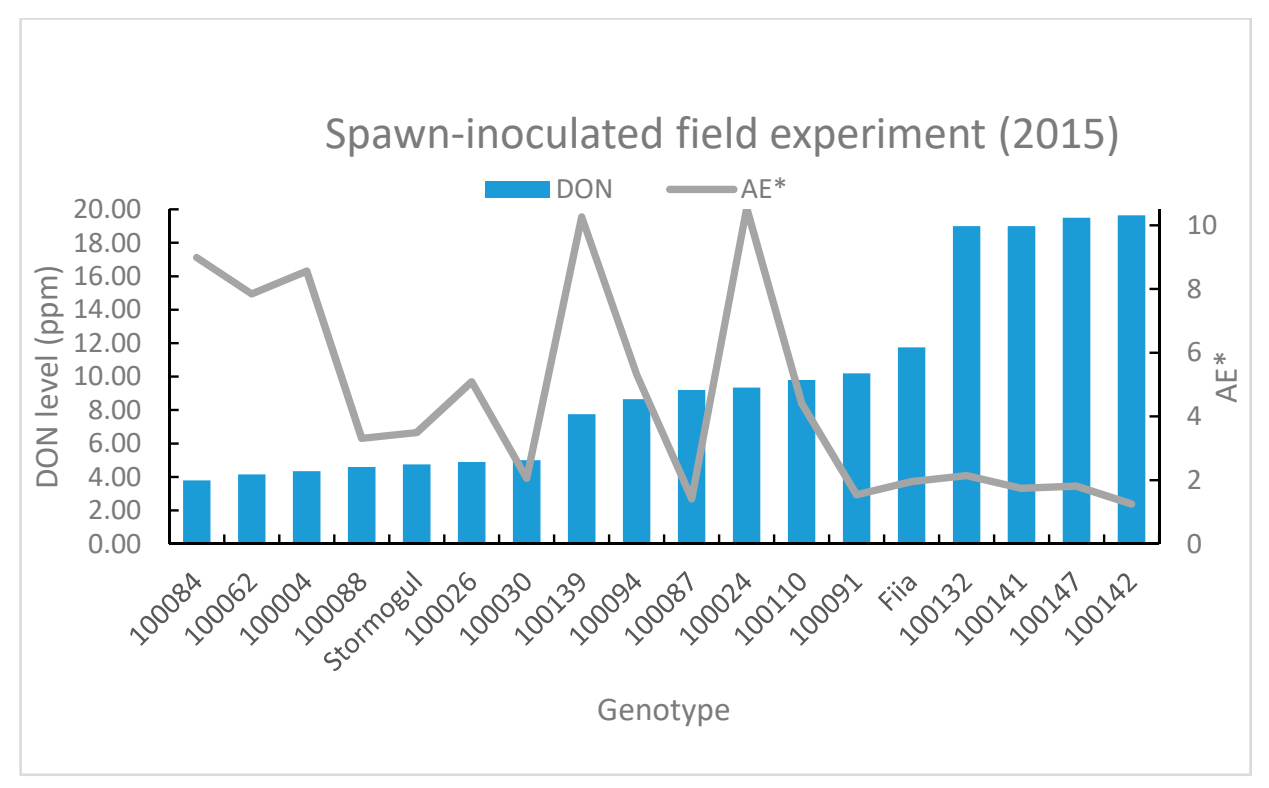

Figure 4. Mean deoxynivalenol content (DON and anther extrusion ( $\mathrm{AE}^{*}$, estimated from average number of remaining anthers $(\mathrm{AR})$ using the formula $\left.\mathrm{AE}=2.71^{(3-\mathrm{AR})}\right)$ in a spawn-inoculated field experiment using selected recombinant inbred lines from the Fiia by Stormogul population and the parents. 

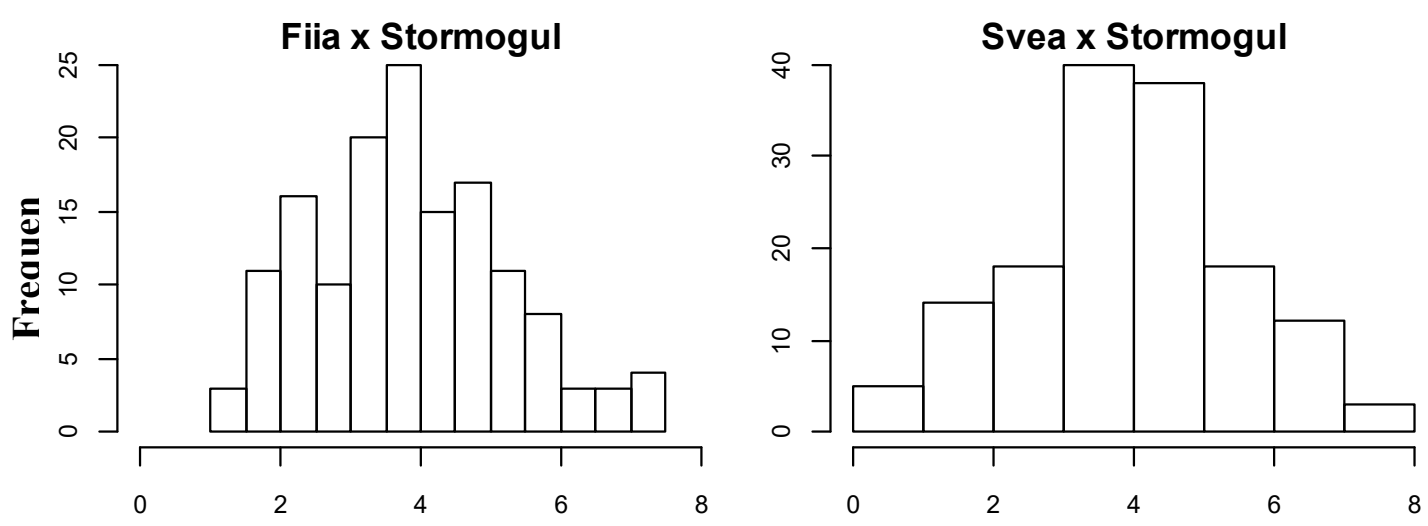

Anther Extrusion (0-9)

Figure 5. Distribution of BLUP values for anther extrusion in the Fiia by Stormogul (Left) and Svea by Stormogul (Right) recombinant inbred line populations averaged for 2012 and 2013. Anther extrusion was scored on a scale of 0 to 9 .

In $\mathrm{F} \times \mathrm{S}, \mathrm{AE}^{*}$ and FHB were negatively correlated $(r=-0.6, p<0.01)$, as were $\mathrm{AE}^{*}$ and DON $(r=-0.5, p<0.01)$ (Table 4$)$, meaning that RILs with high $\mathrm{AE}^{*}$ had lower DON values and FHB scores. Days to flowering did not correlate significantly with FHB nor with DON levels (Table 4). The correlations between $\mathrm{AE}$ and $\mathrm{FHB}$ and between $\mathrm{AE}$ and $\mathrm{DON}$ in $\mathrm{S} \times \mathrm{S}$ were also negative, but not significant (Table 4).

Table 4. Pearson's correlation analysis among different agronomic and Fusarium head blight (FHB) traits from spawn-inoculated field experiments using selected RILs from $\mathrm{F} \times \mathrm{S}$ and $\mathrm{S} \times \mathrm{S}$ populations. Data from the recombinant inbred lines only was used for analysis. Anther extrusion (AE*) was calculated from anther retention $(\mathrm{AR})$ using the formula $\mathrm{AE}=2.71^{(3-\mathrm{AR})} . \mathrm{F} \times \mathrm{S}$ : Fiia by Stormogul cross, $\mathrm{S} \times \mathrm{S}$ : Svea by Stormogul cross, DON: Deoxynivalenol content, FHB: field Fusarium head blight scores, DTF: Days to flowering. ${ }^{* *} p<0.01,{ }^{*} p<0.05$, and ns: non-significant.

\begin{tabular}{cccccccc}
\hline $\mathbf{F} \times \mathbf{S}$ & DON & FHB & DTF & S $\times \mathbf{S}$ & DON & FHB & DTF \\
\hline FHB & $0.57^{* *}$ & & & FHB & $0.03^{\mathrm{ns}}$ & & \\
DTF & $-0.16^{\mathrm{ns}}$ & $-0.34^{\mathrm{ns}}$ & & DTF & $-0.42^{*}$ & $-0.29^{\mathrm{ns}}$ & \\
AE $^{*}$ & $-0.51^{* *}$ & $-0.58^{* *}$ & $0.19^{\mathrm{ns}}$ & AE & $-0.21^{\mathrm{ns}}$ & $0.01^{\mathrm{ns}}$ & $0.40^{*}$ \\
\hline
\end{tabular}

\subsubsection{Spray-Inoculated Greenhouse Experiment}

In the spray inoculated greenhouse experiment, mean DON levels ranged from $5.6 \mathrm{ppm}$ to $60.4 \mathrm{ppm}$, with Fiia and Stormogul having mean DON values of $5.6 \mathrm{ppm}$ and $7.5 \mathrm{ppm}$, respectively. Statistically significant differences $(p<0.05)$ between the entries were found for DON level, FHB, AE*, and DTF. In the RILs, FHB and DON were highly correlated $(0.9, p<0.001)$, while AE* and FHB only did so weakly $(0.4, p<0.05)$, while $\mathrm{AE}^{*}$ and $\mathrm{DON}$ were uncorrelated. Some high $\mathrm{AE}$ genotypes were so severely infected that not only the whole panicle, but also the peduncle was affected, with mycelium proliferating in the (wilted) flag leaf sheath. Days to flowering was not correlated to any of the traits scored (FHB, DON, and AE).

\section{Discussion}

This paper reports trials conducted to study the variation of $\mathrm{AE}$ and its possible role in Fusarium infection in oat. Anther extrusion and AR have been shown to affect resistance of small-grained cereals to FHB in different studies $[4,16,29,30]$ and QTLs for AE and AR are mapped in wheat $[13,31]$. In wheat NILs, two closely linked FHB QTLs on 5AS were found to coincide with AR and one of them, Qfhs.ifa-5Ac, was stronger than Fhb1. Manual emasculation led to even less infection, directly 
demonstrating their etiological role. Like in wheat, $\mathrm{AE}$ is a trait with high heritability, likely governed by a limited number of genes. Significant relationships between DON and the presence of anthers imply that AE may be a valuable trait for indirect selection for resistance to Fusarium in oat.

\subsection{Variation and Inheritance of Anther Extrusion in Oat}

There was significant variation for $\mathrm{AE}$ in both the screening populations and the RIL populations, but less in the recent Nordic cultivars. This may be a result of indirect selection for uniformity, since open flowering and high AE promote outcrossing was seen [12,32], and higher incidence of smut. Genotypic effects of AE were strong in both RIL populations. Anther extrusion in the RIL populations showed continuous quantitative distribution in both populations, as found in wheat and barley $[12,16]$. The presence of RILs with higher or lower AE values than the parents indicated transgressive segregation for the trait, with both parents adding alleles for higher and lower AE. Transgressive segregation for AE was also detected in wheat and barley $[12,16,33]$. The high heritability for $\mathrm{AE}$ in both populations and the continuous distribution of $\mathrm{AE}$ indicate that a few genes having large to moderate effects control the trait.

\subsection{Effect of Anther Extrusion on Fusarium Head Blight}

Our hypothesis was that, like in wheat, genotypes with intermediate to low AE were more susceptible to FHB [30] than closed- or open-flowering oat genotypes. With low to moderate AE, anthers may be trapped between the palea and lemma. Conversely, genotypes with closed flowering deny access to these tissues and hence escape infection, or high AE (low AR) contain no dead anthers that serve as infection points in small-grained cereals $[15,30]$. The negative correlations between $\mathrm{AE}^{*}$ and $\mathrm{FHB}$ traits in $\mathrm{F} \times \mathrm{S}$ (less in $\mathrm{S} \times \mathrm{S}$ ) conform to these results in wheat and barley.

However, these correlations are indirect across environments, since mist irrigation and wind compromise AE scores in inoculation experiments and must be done in another environment. Any significant correlations between genotypic (BLUP) values then reflect genetic correlations, since $\mathrm{G} \times \mathrm{E}$ and $\mathrm{E}$ (year) effects cannot be correlated. The subsequent studies and the wide adoption of $\mathrm{AE}$ as a breeding trait have corroborated this conclusion reached by Skinnes et al. [16].

Still, the correlations in oat appear weaker than in wheat, most likely due to the strong Type II resistance due to the pedicels in oat. Using selective phenotyping for high and low AE in wheat, like we did here in oat, genetic correlations between DON and AE increased to $>0.8$ [5]. Thus, correlations will be expected to be weaker in random lines and crosses where the range in $\mathrm{AE}$ is limited.

The positive correlations between $\mathrm{AE}^{*}$ and $\mathrm{FHB}$ (and DON) in the spray-inoculated greenhouse experiment need interpretation. The greenhouse plants were spray-inoculated in the afternoon when open flowering occurred. Unlike spawn inoculum, where single ascospores are released into the atmosphere, with spray inoculation, loads of spores land directly in the floret cavity of open flowering genotypes and successfully establish infection. Since AE is an avoidance mechanism, open flowering genotypes will more easily be infected following spray inoculation even if they have high AE. Moreover, the parents and RILs differed unusually much in glume lengths and widths, due to the very long and narrow glumes of Stormogul. It was observed that in the still greenhouse air, anthers hanging from high-AE spikelets were sometimes trapped or stuck between glumes after florets closed. The apparent disparity between $\mathrm{AE}$ in Stormogul (ca. 6 in Figure 5) and $\mathrm{AE}^{*}$ (ca. 3.5 in Figure 5) may reflect that $\mathrm{AE}$ and open flowering do not always coincide.

Our field experiments indicate that AE may be used as a selection trait for FHB resistance, provided that sufficient variation is present in the germplasm pool, which appears most often not to be the case. Anther extrusion scores are less repeatable in the low AE range and in those cases, AR will be most reliable. 


\subsection{Diversity of Nordic Oat}

The association between lemma color and $\mathrm{AE}$ in the screening population is probably historical, due to selection against color and/or loss of AE. However, there is a case for weak linkage between brown glume color and seed shattering [34,35]. High AE and open flowering may also be considered wild type traits, as also observed in the Avena fatua and Avena sterilis (results not shown). Since hull color increases resistance to FHB in barley (purple-seeded genotypes are more resistant than yellow $[29,36]$. the role of hull color in the infection process of Fusarium spp. is interesting to further study in the RIL populations, as the populations comprise several shades of brown and white lines.

Our data (not reported here) indicate no differences in lodicule sizes or filament lengths between high or low AE genotypes, like previously found in wheat [37]. The duration of flower opening and/or the angle of flower opening $[15,37]$ were not measured, but glume tenacity and length may affect angle of opening in oat, as observed when very long glumes trapped anthers after flowering in the greenhouse.

The transgressive segregation in DTF in the greenhouse in 2013 and the 2-3 weeks later DTF in Stormogul may reflect a facultative winter type where a weak vernalization requirement and shorter photoperiod can lead to late flowering [38]. Very little is known about the photoperiod and vernalization genes in oat. The greater variation in AE, DTF and lemma color in older Nordic accessions supports the strong genetic bottleneck in this germplasm pool, revealed by markers [13]. That restricted variation extends beyond $\mathrm{AE}$ is also indicated by the high yielding $\mathrm{C} 3$ families identified in a base broadening program with introgression lines from $A$. sterilis and subsequent recurrent selection [17].

Author Contributions: Formal analysis, X.H.; Funding acquisition, Å.B.; Investigation, S.T., S.S.S., Y.D. and Å.B.; Methodology, S.T., X.H. and Å.B.; Writing - original draft, Å.B.; Writing - review \& editing, S.T. All authors have read and agreed to the published version of the manuscript.

Funding: The work was supported through two grants from the Norwegian Genetic Resources Council, "Broadening the Genetic Base of Oats" (2012-2014) and "Can Genetic Variation in Flowering Biology Reduce Fusarium Infection in Oats?" (2015-2018).

Acknowledgments: The authors thank Yalew Tarkegne and Cecilie Yri for excellent technical assistance in the field experiments. The authors also acknowledge the AFRI CORE project for allowing the use of their oat genotype panel. AFRI CORE is an acronym for the funding agent for the Agriculture National Food Research Initiative of the United States Department of Agriculture and the The Collaborative Oat Research Enterprise (CORE), led by Eric Jackson and Nicholas Tinker.

Conflicts of Interest: The authors declare no conflict of interest.

\section{References}

1. Marshall, A.; Cowan, S.; Edwards, S.; Griffiths, I.; Howarth, C.; Langdon, T.; White, E. Crops that feed the world 9. Oats- a cereal crop for human and livestock feed with industrial applications. Food Secur. 2013, 5, 13-33. [CrossRef]

2. Peterson, D.M. Oat antioxidants. J. Cereal Sci. 2001, 33, 115-129. [CrossRef]

3. Welch, R.W. Nutrient composition and nutritional quality of oats and comparisons with other cereals. In Oats Chemistry and Technology, 2nd ed.; Webster, F.H., Wood, P.J., Eds.; AACC International: St. Paul, MN, USA, 2011; pp. 95-107.

4. Tekle, S.; Dill-Macky, R.; Skinnes, H.; Tronsmo, A.M.; Bjørnstad, Å. Infection process of Fusarium graminearum in oats (Avena sativa L.). Eur. J. Plant. Pathol. 2012, 132, 431-442. [CrossRef]

5. Bjørnstad, Å.; He, X.; Tekle, S.; Klos, K.; Huang, Y.F.; Tinker, N.A.; Skinnes, H. Genetic variation and associations involving Fusarium head blight and deoxynivalenol accumulation in cultivated oat (Avena sativa L.). Plant. Breed. 2017, 136, 620-636. [CrossRef]

6. He, X.; Skinnes, H.; Oliver, R.E.; Jackson, E.W.; Bjørnstad, Å. Linkage mapping and identification of QTL affecting deoxynivalenol (DON) content (Fusarium resistance) in oats (Avena sativa L.). Theor. Appl. Genet. 2013, 126, 2655-2670. [CrossRef]

7. Tekle, S.; Lillemo, M.; Skinnes, H.; Reitan, L.; Buraas, T.; Bjørnstad, Å. Screening of oat accessions for Fusarium head blight resistance using spawn-inoculated field experiments. Crop. Sci. 2018, 58, 143-151. [CrossRef] 
8. Misonoo, G. Ecological and Physiological Studies on the Blooming of Oat Flowers. Ph.D. Thesis, Hokkaido University, Saporo, Japan, 1936.

9. Rajala, A.; Peltonen-Sainio, P. Pollination dynamics, grain weight and grain cell number within the inflorescence and spikelet in oat and wheat. Agric. Sci. 2011, 2, 283-290. [CrossRef]

10. De Vries, A.P. Flowering biology of wheat, particularly in view of hybrid seed production-A review. Euphytica 1971, 20, 152-170. [CrossRef]

11. Nair, S.K.; Wang, N.; Turuspekov, Y.; Pourkheirandish, M.; Sinsuwongwat, S.; Chen, G.; Komatsuda, T. Cleistogamous flowering in barley arises from the suppression of microRNA-guided HvAP2 mRNA cleavage. Proc. Natl. Acad. Sci. USA 2010, 107, 490-495. [CrossRef]

12. Abdel-Ghani, A.H.; Parzies, H.K.; Ceccarelli, S.; Grando, S.; Geiger, H.H. Estimation of quantitative genetic parameters for outcrossing-related traits in barley. Crop. Sci. 2005, 45, 98-105. [CrossRef]

13. Buerstmayr, M.; Buerstmayr, H. Comparative mapping of quantitative trait loci for Fusarium head blight resistance and anther retention in the winter wheat population Capo× Arina. Theor. Appl. Genet. 2015, 128, 1519-1530. [CrossRef] [PubMed]

14. Steiner, B.; Buerstmayr, M.; Michel, S.; Schweiger, W.; Lemmens, M.; Buerstmayr, H. Breeding strategies and advances in line selection for Fusarium head blight resistance in wheat. Trop. Plant. Pathol. 2017, 42, 165-174. [CrossRef]

15. Gilsinger, J.; Kong, L.; Shen, X.; Ohm, H. DNA markers associated with low Fusarium head blight incidence and narrow flower opening in wheat. Theor. Appl. Genet. 2005, 110, 1218-1225. [CrossRef] [PubMed]

16. Skinnes, H.; Semagn, K.; Tarkegne, Y.; Marøy, A.G.; Bjørnstad, Å. The inheritance of anther extrusion in hexaploid wheat and its relationship to Fusarium head blight resistance and deoxynivalenol content. Plant. Breed. 2010, 129, 149-155. [CrossRef]

17. Bushnell, W.R.; Hazen, B.E.; Pritsch, C. Histology and physiology of Fusarium head blight. In Fusarium Head Blight of Wheat and Barley; Leonard, K.J., Bushnell, W.R., Eds.; The American Phytopathological Society: St. Paul, MN, USA, 2003; pp. 44-83.

18. Lewandowski, S.M.; Bushnell, W.R.; Evans, C.K. Distribution of mycelial colonies and lesions in field grown barley inoculated with Fusarium graminearum. Phytopathology 2006, 96, 567-581. [CrossRef]

19. Yoshida, M.; Kawada, N.; Nakajima, T. Effect of infection timing on Fusarium head blight and mycotoxin accumulation in open- and closed-flowering barley. Phytopathology 2007, 97, 1054-1062. [CrossRef]

20. Divon, H.H.; Bøe, L.; Tveit, M.M.N.; Klemsdal, S.S. Histological studies of F. langsethiae infection on oats and wheat. In Proceedings of the Nordic Baltic Fusarium Seminar, Uppsala, Sweden, 13-15 November 2012.

21. He, X.; Bjørnstad, Å. Diversity of north European oat analyzed by SSR, AFLP, and DArT markers. Theor. Appl. Genet. 2012, 125, 57-70. [CrossRef]

22. Mattsson, B. Svensk växtförädling av havre. In Den Svenska Växtförädlingens Historia: Jordbruksväxternas Utveckling Senda 1880-Talet; Olsson, G., Ed.; Kungliga skogs- och lantbruksakademien: Stockholm, Sweden, 1997; p. 320.

23. Scott, R.A.; Milliken, G.A. A SAS program for analyzing augmented randomized complete-block designs. Crop. Sci. 1993, 33, 865-867. [CrossRef]

24. Zadoks, J.C.; Chang, T.T.; Konzak, C.F. A decimal code for the growth stages of cereals. Weed Res. 1974, 14, 415-421. [CrossRef]

25. Tekle, S.; Skinnes, H.; Bjørnstad, A. The germination problem of oat seed lots affected by Fusarium head blight. Eur. J. Plant. Pathol. 2013, 135, 147-158. [CrossRef]

26. Mirocha, C.J.; Kolaczkowski, E.; Xie, W.P.; Yu, H.; Jelen, H. Analysis of deoxynivalenol and its derivatives (batch and single kernel) using gas chromatography mass spectrometry. J. Agric. Food Chem. 1998, 46, 1414-1418. [CrossRef]

27. Fuentes, R.G.; Mickelson, H.R.; Busch, R.H.; Dill-Macky, R.; Evans, C.K.; Thompson, W.G.; Anderson, J.A. Resource allocation and cultivar stability in breeding for Fusarium head blight resistance in spring wheat. Crop. Sci. 2005, 45, 1965-1972. [CrossRef]

28. Choo, T.M.; Vigier, B.; Savard, M.E.; Blackwell, B.; Martin, R.; Wang, J.; Abdel-Aal, E.-S.M. Black barley as a means of mitigating deoxynivalenol contamination. Crop. Sci. 2015, 55, 1096-1103. [CrossRef]

29. Choo, T.M.; Vigier, B.; Shen, Q.Q.; Martin, R.A.; Ho, K.M.; Savard, M. Barley traits associated with resistance to Fusarium head blight and deoxynivalenol accumulation. Phytopathology 2004, 94, 1145-1150. [CrossRef] 
30. Kubo, K.; Fujita, M.; Kawada, N.; Nakajima, T.; Nakamura, K.; Maejima, H.; Matsunaka, H. Minor differences in anther extrusion affect resistance to Fusarium head blight in wheat. J. Phytopathol. 2013, 161, 308-314. [CrossRef]

31. Lu, Q.; Lillemo, M.; Skinnes, H.; He, X.; Shi, J.; Ji, F.; Bjørnstad, Å. Anther extrusion and plant height are associated with Type I resistance to Fusarium head blight in bread wheat line 'Shanghai-3/Catbird'. Theor. Appl. Genet. 2013, 126, 317-334. [CrossRef]

32. Atashi-Rang, G.; Lucken, K. Variability, combining ability, and interrelationships of anther length, anther extrusion, glume tenacity, and shattering in spring wheat. Crop. Sci. 1978, 18, 267-272. [CrossRef]

33. Langer, S.M.; Longin, C.F.H.; Würschum, T. Phenotypic evaluation of floral and flowering traits with relevance for hybrid breeding in wheat (Triticum aestivum L.). Plant. Breed. 2014, 133, 433-441. [CrossRef]

34. Sage, G.C.M.; Isturiz, M.J.D. The inheritance of anther extrusion in two spring wheat varieties. Theor. Appl. Genet. 1974, 45, 126-133. [CrossRef]

35. Ladizinsky, G. Domestication via hybridization of the wild tetraploid oats Avena magna and A. murphyi. Theor. Appl. Genet. 1995, 91, 639-646. [CrossRef]

36. Ladizinsky, G. A synthetic hexaploid $(2 \mathrm{n}=42)$ oat from the cross of Avena strigosa $(2 \mathrm{n}=14)$ and domesticated A. magna $(2 \mathrm{n}=28)$. Euphytica 2000, 116, 231-235. [CrossRef]

37. Arya, R.; Sethi, S. Studies on floral traits influencing outcrossing in wheat (Triticum aestivum L.). Natl. J. Plant. Improv. 2005, 7, 73-76.

38. Holland, J.; Portyanko, V.; Hoffman, D.; Lee, M. Genomic regions controlling vernalization and photoperiod responses in oat. Theor. Appl. Genet. 2002, 105, 113-126. [CrossRef] [PubMed]

(C) 2020 by the authors. Licensee MDPI, Basel, Switzerland. This article is an open access article distributed under the terms and conditions of the Creative Commons Attribution (CC BY) license (http://creativecommons.org/licenses/by/4.0/). 